\title{
ARTICLE
}

\section{Comprehensive Design of the High-Sulfur-Loading Li-S Battery Based on MXene Nanosheets}

Cite as

Nano-Micro Lett.

(2020) 12:112

Received: 25 February 2020

Accepted: 22 April 2020

Published online: 20 May 2020

(C) The Author(s) 2020

\author{
Shouzheng Zhang ${ }^{1,3}$, Ning Zhong ${ }^{2}$, Xing Zhou ${ }^{2}$, Mingjie Zhang ${ }^{2}$, Xiangping Huang ${ }^{3}$, \\ Xuelin Yang ${ }^{1}$, Ruijin Meng ${ }^{2}$, Xiao Liang ${ }^{2} \bowtie$ \\ Shouzheng Zhang and Ning Zhong contributed equally to this work. \\ $\triangle$ Xuelin Yang, xlyang@ctgu.edu.cn; Xiao Liang, xliang@hnu.edu.cn \\ 1 College of Materials and Chemical Engineering, China Three Gorges University, 8 Daxue Road, \\ Yichang 443002, Hubei, People's Republic of China \\ 2 State Key Laboratory of Chem/Biosensing and Chemometrics, College of Chemistry and Chemical \\ Engineering, Hunan University, Changsha 410082, People's Republic of China \\ 3 College of Science, China Three Gorges University, 8 Daxue Road, Yichang 443002, Hubei, \\ People's Republic of China
}

\section{HIGHLIGHTS}

- The intrinsic negatively charged MXene nanosheets were assembled to the positively charged Ketjen black/sulfur (KB/S) or KB to constructing the interwoven composite.

- The KB/S@ $\mathrm{Ti}_{3} \mathrm{C}_{2} \mathrm{~T}_{\mathrm{x}}$ architectures allow high sulfur loading and accommodate the corresponding volume change, while the structural integrity and the ionic and electric conducting pathways are well maintained.

- The $\mathrm{KB} @ \mathrm{Ti}_{3} \mathrm{C}_{2} \mathrm{~T}_{\mathrm{x}}$ interlayers further retard the polysulfide that escaped from the cathode. It is only $0.28 \mathrm{mg} \mathrm{cm}^{-2}$ in density and $3 \mu \mathrm{m}$ in thickness - the effect on energy density is minimal.

\begin{abstract}
The lithium-sulfur battery is the subject of much recent attention due to the high theoretical energy density, but practical applications are challenged by fast decay owing to polysulfide shuttle and electrode architecture degradation. A comprehensive study of the sulfur host microstructure design and the cell architecture construction based on the MXene phase $\left(\mathrm{Ti}_{3} \mathrm{C}_{2} \mathrm{~T}_{x}\right.$ nanosheets) is performed, aiming at realize stable cycling performance of Li-S battery with high sulfur areal loading. The interwoven $\mathrm{KB} @ \mathrm{Ti}_{3} \mathrm{C}_{2} \mathrm{~T}_{x}$ composite formed by self-assembly of MXene and Ktejen black, not only provides superior conductivity and maintains the electrode integrality bearing the volume expansion/shrinkage when used as the sulfur host, but also functions as an interlayer on separator to further retard the polysulfide cross-diffusion that possibly

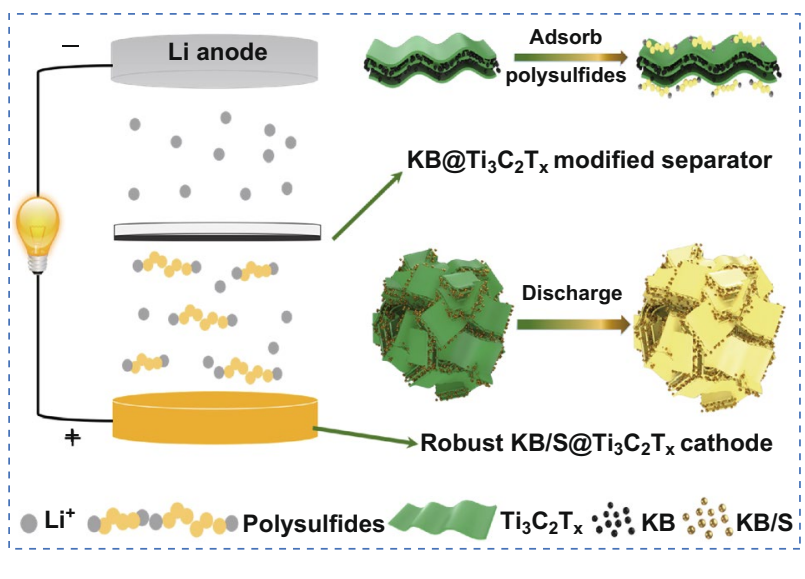
escaped from the cathode. The $\mathrm{KB} @ \mathrm{Ti}_{3} \mathrm{C}_{2} \mathrm{~T}_{x}$ interlayer is only $0.28 \mathrm{mg} \mathrm{cm}{ }^{-2}$ in areal loading and $3 \mu \mathrm{m}$ in thickness, which accounts a little contribution to the thick sulfur electrode; thus, the impacts on the energy density is minimal. By coupling the robust $\mathrm{KB}_{0} \mathrm{Ti}_{3} \mathrm{C}_{2} \mathrm{~T}_{x}$ cathode and the effective $\mathrm{KB} @ \mathrm{Ti}_{3} \mathrm{C}_{2} \mathrm{~T}_{x}$ modified separator, a stable Li-S battery with high sulfur areal loading $\left(5.6 \mathrm{mg} \mathrm{cm}^{-2}\right)$ and high areal capacity $\left(6.4 \mathrm{mAh} \mathrm{cm}^{-2}\right)$ at relatively lean electrolyte is achieved.
\end{abstract}

KEYWORDS MXene nanosheet; High sulfur areal loading; Interlayer; Lithium-sulfur battery 


\section{Introduction}

The ever-increasing demands from portable electronic devices, electric vehicles and renewable energy sources call for energy storage devices that embrace lower cost and higher energy density as well as longer cycling life [1]. Li-S batteries that couple earth-abundant and highcapacity sulfur positive electrodes with lithium negative electrodes are considered among the most promising candidates due to high theoretical specific capacity $(1675 \mathrm{mAh}$ $\mathrm{g}^{-1}$ ) and high theoretical energy density (2600 $\mathrm{Wh} \mathrm{kg}^{-1}$ ) [2]. Nonetheless, obstacles that impede the application of Li-S batteries are fast capacity decay, poor rate capability and low practical energy density. The polysulfide shuttle, low conductive (electric and ionic) of sulfur $/ \mathrm{Li}_{2} \mathrm{~S}$ and low sulfur areal loading associated high electrolyte/sulfur ratio $(E / S)$ are underlying reasons that account for these challenges [3]. Great efforts had been made in the past decades trying to develop advanced Li-S battery with stable performance and high energy density, including new sulfur host material exploration [4-6], electrolyte formula optimization [7, 8], and robust electrode/cell architecture construction [9-11]. Among them, functional sulfur host materials with variety microstructures and surface properties are the main research streams that were anticipated to entrap polysulfide in the cathode $[12,13]$. Indeed, the polysulfide physi-/chemisorption strategies are promising to suppress the detrimental shuttle effect [14-16]. These approaches have shortened the gap between research and application for $\mathrm{Li}-\mathrm{S}$ batteries.

We discovered that the MXene phase, a fascinating twodimensional material with decent conductivity, demonstrating strong Lewis acid-based interaction with lithium polysulfides by metal-sulfur ( $\mathrm{S}-\mathrm{Ti}-\mathrm{C}$ ) binding at the interface [4]. We further elucidated that the cleavage of the hydroxyl terminal group from MXene contributes to retardation of polysulfide dissolution by another well-established mechanism-the thiosulfate-polythionate conversion $[17,18]$. Benefitted from the high electric conductivity and rich surface properties that could synergistically improve the electron transport properties of the sulfur electrode and provide chemical interactions with polysulfides, MXene is regarded as one of the most promising sulfur host candidates [19]. Moreover, MXene has also been applied to various batteries due to the excellent electrochemical performance [20,21].
Note that solely relying on these polysulfide confinement strategies in practical cells could partially alleviate the shuttling effect because of the relatively low fraction of the electrochemically inert host material in the electrode. Insertion of interlayers between the separator and the cathode has been demonstrated to further alleviate the polysulfide shuttle [22-24]; however, debates have been taken place because this interlayer inevitably sacrifices the volumetric/gravimetric density of the battery. MXene nanosheets have been successfully applied as the interlayer to improve the stability of the $\mathrm{Li}-\mathrm{S}$ battery $[25,26]$. The potential of the interlayer approach towards practical application relies on how thick and what a small weight ratio could the interlayer be manufactured.

While the techno-economic analysis suggests that cathodes of Li-S battery with areal capacity of $4 \mathrm{mAh} \mathrm{cm}^{-2}$ are necessary to compete with state-of-the-art Li-ion technology [12], the thick electrodes are challenged by volume expansion and poor kinetics. Designing architectures that could accommodate a large amount of sulfur and the corresponding volume change, effectively entrap the polysulfides, and maintain the ionic and electronic conducting pathways over cycling are highly desired $[14,27]$. Optimized architectures such as microporous electrode $[28,29]$, three-dimensional framework electrodes [30, $31]$, and cross-linking sulfur hosts [32, 33] are pleasurable alternative approach towards high-performance $\mathrm{Li}-\mathrm{S}$ batteries .

Herein, we performed comprehensive material design and cell architecture construction based on the above MXene phase $\left(\mathrm{Ti}_{3} \mathrm{C}_{2} \mathrm{~T}_{x}\right.$ nanosheets), aiming at realizing stable cycling performance of Li-S battery with high sulfur areal loading. The intrinsic negatively charged MXene nanosheets were assembled to the positively charged Ketjen black/sulfur $(\mathrm{KB} / \mathrm{S})$ particles to construct the interwoven $\mathrm{KB} / \mathrm{S} @ \mathrm{Ti}_{3} \mathrm{C}_{2} \mathrm{~T}_{x}$ composite. While the Ketjen black core improves the electric conductivity for the sulfur, the $\mathrm{Ti}_{3} \mathrm{C}_{2} \mathrm{~T}_{x}$ guarantees physi-/chemisorption of the soluble polysulfide species and further enhances the in-plane conductivity. More importantly, the self-assembled secondary particle structure benefits the structure integrality bearing the volume expansion/shrinkage of the sulfur electrode. The $\mathrm{KB} @ \mathrm{Ti}_{3} \mathrm{C}_{2} \mathrm{~T}_{x}$ prepared by similar self-assembly approach was coated on commercial separator to further retard the polysulfide that possibly escaped from the cathode. The $\mathrm{KB} @ \mathrm{Ti}_{3} \mathrm{C}_{2} \mathrm{~T}_{x}$ interlayer, only $0.28 \mathrm{mg} \mathrm{cm}^{-2}$ in areal loading and $3 \mu \mathrm{m}$ in thickness, accounts a little contribution to the volume and the mass of the thick electrode; thus, the effect on the energy density is minimal. By coupling the robust KB@ 
$\mathrm{Ti}_{3} \mathrm{C}_{2} \mathrm{~T}_{x}$ cathode and the effective $\mathrm{KB} @ \mathrm{Ti}_{3} \mathrm{C}_{2} \mathrm{~T}_{x}$ modified separator, we achieved a stable Li-S battery with high sulfur areal loading $\left(5.6 \mathrm{mg} \mathrm{cm}^{-2}\right)$ and high areal capacity $(6.4 \mathrm{mAh}$ $\mathrm{cm}^{-2}$ ) at relatively lean electrolyte.

\section{Experimental Section}

\subsection{Synthesis of $\mathrm{Ti}_{3} \mathrm{C}_{2} \mathrm{~T}_{x}$}

$\mathrm{Ti}_{3} \mathrm{C}_{2} \mathrm{~T}_{x}$ colloidal solution was synthesized by liquid-phase delamination of $\mathrm{Ti}_{3} \mathrm{AlC}_{2}$ powder [34]. Typically, $2 \mathrm{~g} \mathrm{LiF}$ was added to $40 \mathrm{~mL}$ of $9 \mathrm{M} \mathrm{HCl}$ and stirred for $10 \mathrm{~min}$, followed by slowly addition of $2 \mathrm{~g} \mathrm{Ti}_{3} \mathrm{AlC}_{2}$. The etching reaction was held at room temperature for $24 \mathrm{~h}$ under magnetic stirring. The resultant was washed and centrifuged with deionized water until the $\mathrm{pH}$ of the supernatant was approximately 6 . Subsequently, the precipitate was mixed with deionized water and sonicated under Ar-protected environment for $1 \mathrm{~h}$ and centrifuged at $3500 \mathrm{rpm}$ for $1 \mathrm{~h}$ to remove any large particles.

\subsection{Synthesis of KB/S Composite}

The KB/S composite was produced by liquid phase method as reported elsewhere [35]. Briefly, $1.8 \mathrm{~g}$ sulfur and $0.25 \mathrm{~g}$ Ketjen black (KB) were added into $50 \mathrm{~mL}$ ethanediamine (EDA) with stirring for $20 \mathrm{~min}$, then $8 \% \mathrm{HNO}_{3}$ solution was slowly added into the mixture until the $\mathrm{pH} \approx 6$. After magnetic stirring for $2 \mathrm{~h}$, the KB/S composite was collected by filtering and washing with DI water followed by drying at $60^{\circ} \mathrm{C}$ for $24 \mathrm{~h}$.

\subsection{Synthesis of $\mathrm{KB} / \mathrm{S} @ \mathrm{Ti}_{3} \mathrm{C}_{2} \mathrm{~T}_{x}$ Composite}

$0.155 \mathrm{~g}$ of $\mathrm{KB} / \mathrm{S}$ composite and $0.3 \mathrm{~g}$ poly(ethylenimine) were dispersed evenly in $150 \mathrm{~mL}$ DI water by sonication. Next, the solid was collected by vacuum filtration and then re-dispersed in $150 \mathrm{~mL}$ water. $\mathrm{Ti}_{3} \mathrm{C}_{2} \mathrm{~T}_{x}$ with the concentration of $0.5 \mathrm{mg} \mathrm{L}^{-1}$ was added to the above suspension and stirred for $2 \mathrm{~h}$. The product was washed with DI water and dried in vacuum for $24 \mathrm{~h}$.

\subsection{Preparation of $\mathrm{KB} @ \mathrm{Ti}_{3} \mathrm{C}_{2} \mathrm{~T}_{x}$-coated Separators}

The synthesis method of the $\mathrm{KB} @ \mathrm{Ti}_{3} \mathrm{C}_{2} \mathrm{~T}_{x}$ composite (KB: $\mathrm{Ti}_{3} \mathrm{C}_{2} \mathrm{~T}_{x}=2: 8, \mathrm{w} / \mathrm{w}$ ) is similar to the $\mathrm{KB} / \mathrm{S} @ \mathrm{Ti}_{3} \mathrm{C}_{2} \mathrm{~T}_{x}$ composite. The $\mathrm{KB} @ \mathrm{Ti}_{3} \mathrm{C}_{2} \mathrm{~T}_{x}$ was added to $0.2 \mathrm{wt} \%$ polyvinylidene fluoride (PVDF) solution with $\mathrm{N}$-methyl2-pyrrolidinone solution (NMP) as solvent where a ratio of $\mathrm{KB} @ \mathrm{Ti}_{3} \mathrm{C}_{2} \mathrm{~T}_{x} / \mathrm{PVDF}$ was 9:1. The slurry was then cast onto commercial separator (Celgard 2500) and dried in a vacuum oven at $50{ }^{\circ} \mathrm{C}$ overnight.

\subsection{Material Characterization}

XRD measurements were carried out on X-ray diffraction (XRD, Rigaku RINT-2000) with $\mathrm{Cu} \mathrm{K} \alpha$ radiation. SEM studies were carried out on a JSM-6700Femission SEM instrument. TEM studies were carried out on highresolution transmission electron microscopy (HRTEM Philips TecnaiF20, $200 \mathrm{kV}$ ). Thermogravimetric analysis conducted on DTG-60 instrument was used to determine the sulfur content of the composite under an argon flow. Brunauer-Emmett-Teller (BET) measurements were carried out on a JW-BK200C surface area analyzer operating at nitrogen atmosphere and the adsorption temperature of $77 \mathrm{k}$. Samples were dried for $24 \mathrm{~h}$ in vacuum at $60^{\circ} \mathrm{C}$ prior to the characterization.

\subsection{Electrochemical Measurements}

The electrodes were fabricated by casting a slurry containing $80 \mathrm{wt} \%$ active material (i.e., $\mathrm{KB} / \mathrm{S}$ or $\mathrm{KB} / \mathrm{S} @ \mathrm{Ti}_{3} \mathrm{C}_{2} \mathrm{~T}_{x}$ ), $5 \mathrm{wt} \%$ super P, $5 \mathrm{wt} \% \mathrm{CNT}$, and $10 \mathrm{wt} \% \mathrm{La} 133$ on carbon paper (HCP020N, Shanghai Hesen) and dried at $60^{\circ} \mathrm{C}$. The diameter of the electrode is $10 \mathrm{~mm}$ in diameter, and the sulfur loading is about $1.5 \mathrm{mg} \mathrm{cm}^{-2}$. CR2032-type coin cells were assembled in an argon-filled glove box. Lithium foil was used as the anode, and $1 \mathrm{M}$ LiTFSI in 1, 2-dimethoxyethane (DME): 1, 3-dioxolane (DOL) (1:1 vol) with $2 \mathrm{wt} \%$ $\mathrm{LiNO}_{3}$ additive was used as the electrolyte. The batteries were galvanostatic charge/discharge cycled between 1.7 and $2.8 \mathrm{~V}$ on LAND battery tester. Cyclic voltammetry (CV) tests were performed on a VMP-3 workstation (Bio-logic) 
at a scan rate of $0.1 \mathrm{mV} \mathrm{s}^{-1}$ between 1.5 and $3.0 \mathrm{~V}$. Electrochemical impedance spectroscopy (EIS) tests were carried out at a frequency range of $10 \mathrm{mHz}$ to $100 \mathrm{kHz}$ on the same workstation.

\subsection{Polysulfides Adsorption Test}

Polysulfides solution $\left(\mathrm{Li}_{2} \mathrm{~S}_{6}\right)$ was prepared by mixing lithium sulfides $\left(\mathrm{Li}_{2} \mathrm{~S}\right)$ and sulfur powder at a molar ratio of 5:1 in DME followed by magnetic stirring at $60{ }^{\circ} \mathrm{C}$. Then $15 \mathrm{mg}$ of the samples $\left(\mathrm{KB}\right.$ or $\left.\mathrm{KB} @ \mathrm{Ti}_{3} \mathrm{C}_{2} \mathrm{~T}_{x}\right)$ were added to $5 \mathrm{~mL}$ of $1.5 \mathrm{mM} \mathrm{Li}_{2} \mathrm{~S}_{6}$ in DME.

\section{Results and Discussion}

\subsection{Robust KB/S@ $\mathrm{Ti}_{3} \mathrm{C}_{2} \mathrm{~T}_{x}$ Composite Bears Volume Change}

MXene is a negatively charged material due to its surface functional groups [36], which is widely used to synthesize the nanosized composites by self-assembly through electrostatic interaction with the positively charged nanoscale components [37]. We used this self-assembly approach to construct an interwoven structure of the KB/S@ $\mathrm{Ti}_{3} \mathrm{C}_{2} \mathrm{~T}_{x}$ composites, as schematically illustrated in Fig. 1a.

The KB/S core was firstly prepared by a liquid phase method instead of melt-diffusion to avoid uneven sulfur distribution at high sulfur content (see Methods). The KB/S particles were then positively charged by poly(ethyleneimine) (PEI) in aqueous solution, due to the positive charge from the high density of amines [38]. As shown in Fig. 1b, the zeta potential of the $\mathrm{Ti}_{3} \mathrm{C}_{2} \mathrm{~T}_{x}$ nanosheets and the PEI-decorated $\mathrm{KB} / \mathrm{S}$ was measured to be -21 and $40 \mathrm{mV}$, respectively. Before mixing, the individual $\mathrm{KB} / \mathrm{S}$ and $\mathrm{Ti}_{3} \mathrm{C}_{2} \mathrm{~T}_{x}$ aqueous solution are homogenous suspensions due to charge repulsion; however, they precipitated rapidly upon mixing through electrostatic interaction with the zeta potential neutralized to $7 \mathrm{mV}$ (Fig. 1c). SEM images (Fig. 1d, e) reveal the homogenous $\mathrm{KB} / \mathrm{S}$ composites with interconnected nano-size $\mathrm{KB} / \mathrm{S}$ particles in the absence of aggregation. The sulfur content of the $\mathrm{KB} / \mathrm{S}$ composite is determined to be $82 \mathrm{wt} \%$ (Fig. S1). KB/S composite was uniformly assembled to the MXene nanosheets due to electrostatic interaction and further aggregated to form secondary particles with a size of about 10 microns (Fig. 1f, g). TGA reveals the sulfur content in the final composite is about $60 \mathrm{wt} \%$ (Fig. S1). EDS elemental mapping (Fig. S2) indicates the homogeneous distribution of sulfur, carbon and $\mathrm{Ti}_{3} \mathrm{C}_{2} \mathrm{~T}_{x}$ nanosheets in the composite. The KB/S@ $\mathrm{Ti}_{3} \mathrm{C}_{2} \mathrm{~T}_{x}$ composite has the advantage of highly conductive core that is provided by the $\mathrm{KB}$ carbon with unique branched structure and high surface area [39], while the MXene guarantees physi-/chemisorption for the soluble polysulfide species and further enhances the in-plane conductivity [40]. Most importantly, this interwoven structure benefits the structure integrality for the volume expansion/shrinkage of the sulfur electrode, as will be discussed next. The $\mathrm{KB} / \mathrm{S} @ \mathrm{Ti}_{3} \mathrm{C}_{2} \mathrm{~T}_{x}$ is compromised by $60 \mathrm{wt} \%$ sulfur, $13 \mathrm{wt} \% \mathrm{~KB}$ and $27 \mathrm{wt} \% \mathrm{Ti}_{3} \mathrm{C}_{2} \mathrm{~T}_{x}$ nanosheets. The TEM image and $\mathrm{X}$-ray diffraction pattern of the $\mathrm{Ti}_{3} \mathrm{C}_{2} \mathrm{~T}_{x}$ are shown in Fig. S3. The TEM image shows the as-prepared $\mathrm{Ti}_{3} \mathrm{C}_{2} \mathrm{~T}_{x}$ nanosheets are almost monolayer in thickness with several micron in 2-D size. XRD pattern proves the $\mathrm{Ti}_{3} \mathrm{C}_{2} \mathrm{~T}_{x}$ are well exfoliated $[9,25]$. Figure $\mathrm{S} 4$ shows the XRD patterns of KB/S and KB/S@ $\mathrm{Ti}_{3} \mathrm{C}_{2} \mathrm{~T}_{x}$, proving the sulfur maintains in the orthorhombic phase, and the MXene (002) plane is clearly shown in the $\mathrm{KB} / \mathrm{S} @ \mathrm{Ti}_{3} \mathrm{C}_{2} \mathrm{~T}_{x}$ composite.

It is well accepted that the full conversion of sulfur to $\mathrm{Li}_{2} \mathrm{~S}$ results in a volumetric expansion over $80 \%$, which brought huge challenges to the long-term cycling of $\mathrm{Li}-\mathrm{S}$ battery [41]. It attributes to the mechanical degradation of the conductive network in electrode, leading to irreversible structural destruction with a decrease in mechanical integrity and the subsequent rapid capacity decay, especially in the case of high-sulfur-loaded electrodes [42]. Materials engineering to build smart cathode architectures that allow high sulfur loading and accommodate the corresponding volume change, while maintain the structural integrity and the ionic and electric conducting pathways, is highly desired [13].

We systematically evaluated the electrode structure evolution during cycling. Figure 2 compares the SEM images of the KB/S and the KB/S@ $\mathrm{Ti}_{3} \mathrm{C}_{2} \mathrm{~T}_{x}$ electrode, in the initiate state and in the cycled state, respectively. Both $\mathrm{KB} / \mathrm{S}$ and the $\mathrm{KB} / \mathrm{S} @ \mathrm{Ti}_{3} \mathrm{C}_{2} \mathrm{~T}_{x}$ particles are interconnected compactly in their fresh electrodes, as clearly demonstrated by the surface and the cross-sectional SEM images (Fig. 2a, c, e, g). After 10 cycles, conspicuous damage and cracks occurred on the surface of $\mathrm{KB} / \mathrm{S}$ cathode (Fig. 2d). In contrast, no significant change is detected for the KB/S@ $\mathrm{Ti}_{3} \mathrm{C}_{2} \mathrm{~T}_{x}$ 

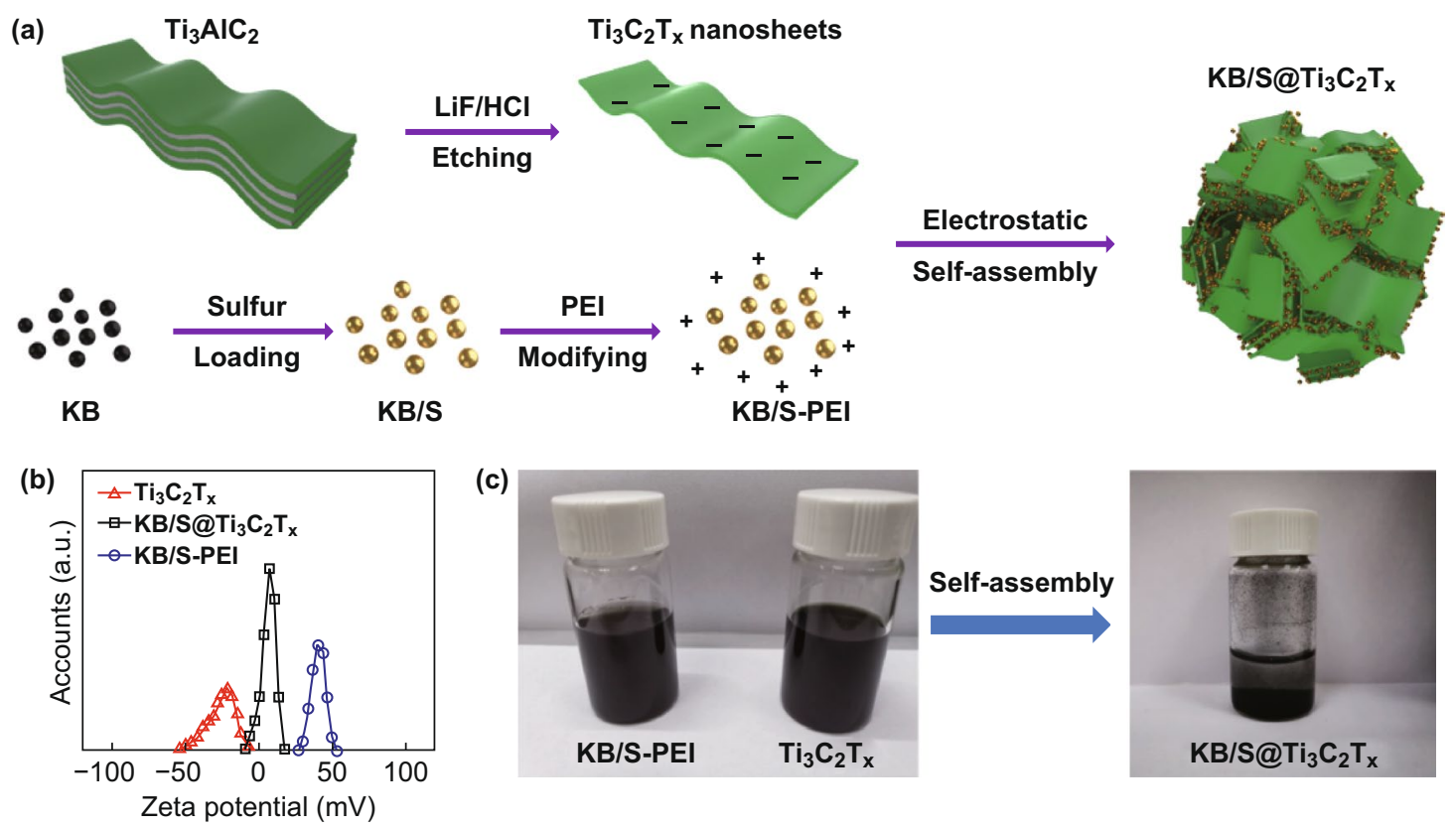

(c)
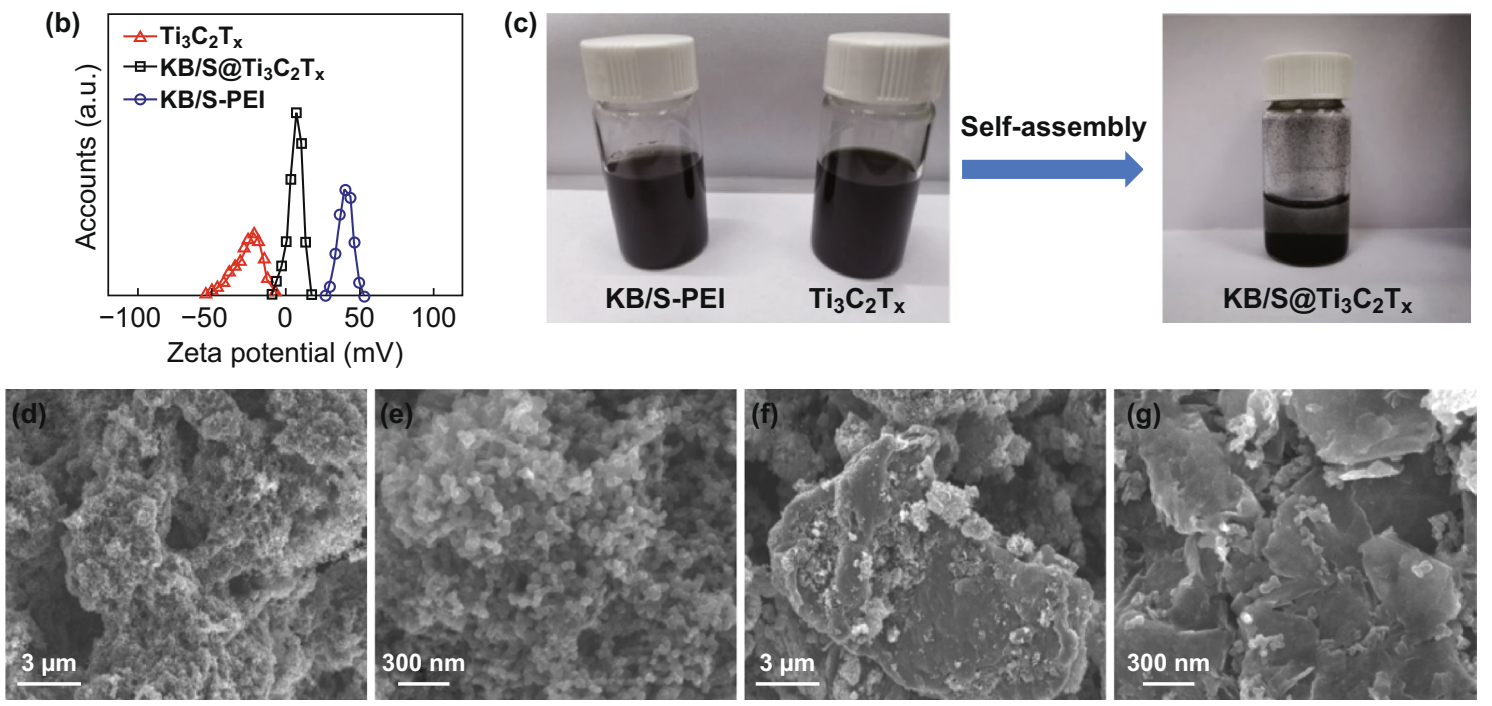

Fig. 1 a Schematic illustration of the fabrication of the KB/S@ $\mathrm{Ti}_{3} \mathrm{C}_{2} \mathrm{~T}_{x}$ composite. b Zeta potential of $\mathrm{Ti}_{3} \mathrm{C}_{2} \mathrm{~T}_{x}$ nanosheets, KB/S-PEI and $\mathrm{KB} / \mathrm{S} @ \mathrm{Ti}_{3} \mathrm{C}_{2} \mathrm{~T}_{x}$. c Digital photographs of KB/S-PEI, $\mathrm{Ti}_{3} \mathrm{C}_{2} \mathrm{~T}_{x}$, and $\mathrm{KB} / \mathrm{S} @ \mathrm{Ti}_{3} \mathrm{C}_{2} \mathrm{~T}_{x}$ aqueous suspension. SEM images of KB/S $(\mathbf{d}, \mathbf{e})$ and $\mathrm{KB} / \mathrm{S} @$ $\mathrm{Ti}_{3} \mathrm{C}_{2} \mathrm{~T}_{x}(\mathbf{f}, \mathbf{g})$

electrode (Fig. 2b). The cross-sectional SEM images give more detailed information about the electrode architecture. Both electrodes have identical thickness before cycling. The $\mathrm{KB} / \mathrm{S} @ \mathrm{Ti}_{3} \mathrm{C}_{2} \mathrm{~T}_{x}$ electrode slightly expands about $18 \%$ with tightly connected particles (Fig. 2e, f), while the KB/S electrode shrinks upon charge and leaves cracks and holes in the electrode (Fig. 2g, h). We assume polysulfide dissolution accounts for the shrinkage of the $\mathrm{KB} / \mathrm{S}$ electrode, resulting in active material loss and leaves holes in the electrode. The difference reflects that the $\mathrm{KB} / \mathrm{S} @ \mathrm{Ti}_{3} \mathrm{C}_{2} \mathrm{~T}_{x}$ composite has the capacity to maintain the active materials in the electrode owing to both physical and chemical confinement provided by the MXene nanosheets. Meanwhile, the interwoven structure could accommodate the volume change, thus effectively maintaining the electrode integrity during cycling.

The electrochemical performance was evaluated in coin cells with conventional electrolyte (1 M LiTFSI in
DOL-DME with $2 \mathrm{wt} \% \mathrm{LiNO}_{3}$ ). Figure 3 a shows the charge/discharge curves of $\mathrm{KB} / \mathrm{S} @ \mathrm{Ti}_{3} \mathrm{C}_{2} \mathrm{~T}_{x}$ cathode at different current densities between 1.7 and $2.8 \mathrm{~V}$. Two distinct voltage plateaus are clearly presented with the higher one corresponding to high-order polysulfide formation and the lower one referring to solid $\mathrm{Li}_{2} \mathrm{~S}$ nucleation, respectively. The polarization between charge and discharge process is increasing as the function of the increased current density. Accordingly, the discharge plateaus are shifted to lower potential. The KB/S cathode shows similar charge/discharge curves; however, the polarization is much greater upon increasing the current density. For example, the KB/S@ $\mathrm{Ti}_{3} \mathrm{C}_{2} \mathrm{~T}_{x}$ electrode has two distinct plateau, but the KB/S electrode only exhibits one slopping curve at $2 \mathrm{C}$ (Figs. $3 \mathrm{a}$, and S5). The difference in polarization indicates the sulfur redox kinetic was improved in $\mathrm{KB} / \mathrm{S} @ \mathrm{Ti}_{3} \mathrm{C}_{2} \mathrm{~T}_{x}$ electrode, which was further supported by the lower charge-transfer 

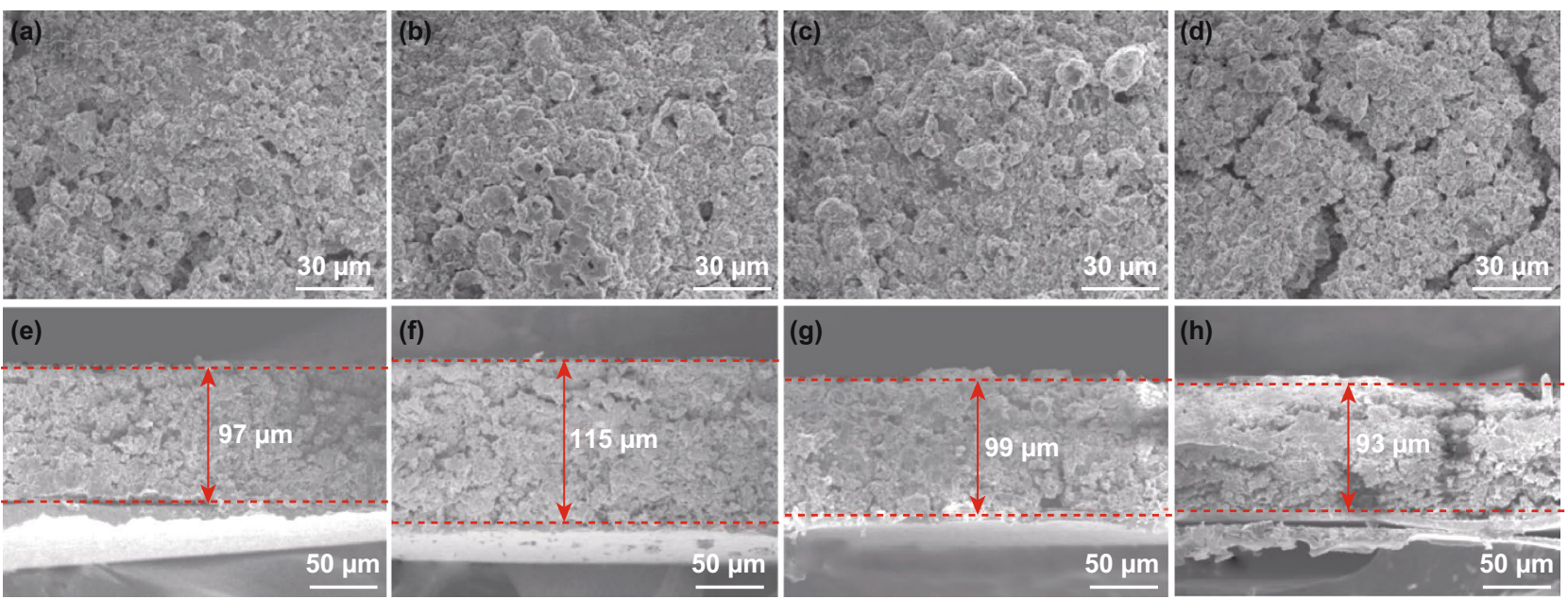

Fig. 2 Comparison of the sulfur electrode by SEM. Surface images of a fresh KB/S@ $\mathrm{Ti}_{3} \mathrm{C}_{2} \mathrm{~T}_{x}$ electrode, $\mathbf{b} \mathrm{KB} / \mathrm{S} @ \mathrm{Ti}_{3} \mathrm{C}_{2} \mathrm{~T}_{x}$ electrode after 10 cycles, $\mathbf{c}$ fresh KB/S electrode, $\mathbf{d ~ K B / S}$ electrode after 10 cycles. Cross-sectional images e before cycle and $\mathbf{f}$ after 10 cycles of the KB/S@ $\mathrm{Ti}_{3} \mathrm{C}_{2} \mathrm{~T}_{x}$ electrode, $\mathbf{g}$ fresh $\mathrm{KB} / \mathrm{S}$ electrode and $\mathbf{h}$ after 10 cycles of the $\mathrm{KB} / \mathrm{S}$ electrode

resistance in the electrochemical impedance spectrum (EIS) (Fig. 3f). Obviously, the MXene nanosheets assembled to $\mathrm{KB} / \mathrm{S}$ particles provide better electric conductivity of the composite, facilitating the charge transfer process and promote the redox kinetics.

We witness a superior rate performance of the KB/S@ $\mathrm{Ti}_{3} \mathrm{C}_{2} \mathrm{~T}_{x}$ electrode (Fig. 3b) than that of the KB/S electrode (Fig. S6). The KB/S@ $\mathrm{Ti}_{3} \mathrm{C}_{2} \mathrm{~T}_{x}$ electrode delivers high specific capacities of $1062,756,634$, and $517 \mathrm{mAh} \mathrm{g}^{-1}$ at the rate of $0.2,0.5,1$, and $2 \mathrm{C}$, respectively. However, the $\mathrm{KB} / \mathrm{S}$ cathode showed lower discharge capacity of $622,480,358$, $156 \mathrm{mAh} \mathrm{g}^{-1}$ at the same rates, respectively (Fig. S6). The $\mathrm{KB} / \mathrm{S} @ \mathrm{Ti}_{3} \mathrm{C}_{2} \mathrm{~T}_{x}$ cathode conveys better cycling performance than the $\mathrm{KB} / \mathrm{S}$ electrode, as exemplified by long-term cycling at $0.2 \mathrm{C}$ (Fig. 3c). After 100 cycles, the discharge capacity of the KB/S@ $\mathrm{Ti}_{3} \mathrm{C}_{2} \mathrm{~T}_{x}$ electrode was $812 \mathrm{mAh} \mathrm{g}^{-1}$, while that of the $\mathrm{KB} / \mathrm{S}$ electrode was only $603 \mathrm{mAh} \mathrm{g}^{-1}$ in the same test condition (Fig. 3c). Longer cycling was conducted at $0.5 \mathrm{C}$, showing a very stable performance over 400 cycles (Fig. 3d). We attribute the improved electrochemical performance of the $\mathrm{KB} / \mathrm{S} @ \mathrm{Ti}_{3} \mathrm{C}_{2} \mathrm{~T}_{x}$ electrode to the optimized interwoven structure, which provides better conductivity while suppresses the polysulfide dissolution via physical and chemical confinement. Given the fact that the $\mathrm{KB} / \mathrm{S} @ \mathrm{Ti}_{3} \mathrm{C}_{2} \mathrm{~T}_{x}$ electrode provides enhanced robustness of the structure integrity as discussed above, we are allowed to cycle the cell with higher sulfur areal loading. Figure $3 \mathrm{e}$ shows the KB/S@ $\mathrm{Ti}_{3} \mathrm{C}_{2} \mathrm{~T}_{x}$ electrode with sulfur loading of
$4.5 \mathrm{mg} \mathrm{cm}^{-2}$. The battery was activated at $0.05 \mathrm{C}$ for the first two cycles followed by long-term cycling at $0.2 \mathrm{C}$. The discharge capacities are 920 and $655 \mathrm{mAh} \mathrm{g}^{-1}$ at 0.05 and $0.2 \mathrm{C}$, respectively. The capacity retains $551 \mathrm{mAh} \mathrm{g}^{-1}$ after 100 cycles. In sharp contrast, KB/S batteries exhibited lower capacity and decayed rapidly even at lower sulfur areal loading $\left(2.6 \mathrm{mg} \mathrm{cm}^{-2}\right)$, as shown in Fig. $3 \mathrm{e}$.

\subsection{Effective $\mathrm{KB} @ \mathrm{Ti}_{3} \mathrm{C}_{2} \mathrm{~T}_{x}$ Further Improves the Sulfur Utilization}

Though effective, the specific capacity that $\mathrm{KB} @ \mathrm{Ti}_{3} \mathrm{C}_{2} \mathrm{~T}_{x}$ composite delivered is not satisfactory, as discussed above. Further improvement of the sulfur utilization in the composite depends on the extent of the polysulfide shuttle that could be suppressed [43]. The combination of physical and chemical confinement of the polysulfide in the KB@ $\mathrm{Ti}_{3} \mathrm{C}_{2} \mathrm{~T}_{x}$ composite, however, is not sufficient due to two reasons. First, the electrostatic interaction that accounts for the self-assembly of the $\mathrm{KB} / \mathrm{S} @ \mathrm{Ti}_{3} \mathrm{C}_{2} \mathrm{~T}_{x}$ composite is not as strong as the covalent bonds, which leaves space at the junction of the two overlapped MXene nanosheets for electrolyte penetration but also allows polysulfide escape. Second, the chemical adsorption of polysulfide is normally based on 'monolayer' interaction with the interface, which is not sufficient to trap the polysulfide, especially at a high sulfur content. Though the polysulfide adsorption capacity 
(a)

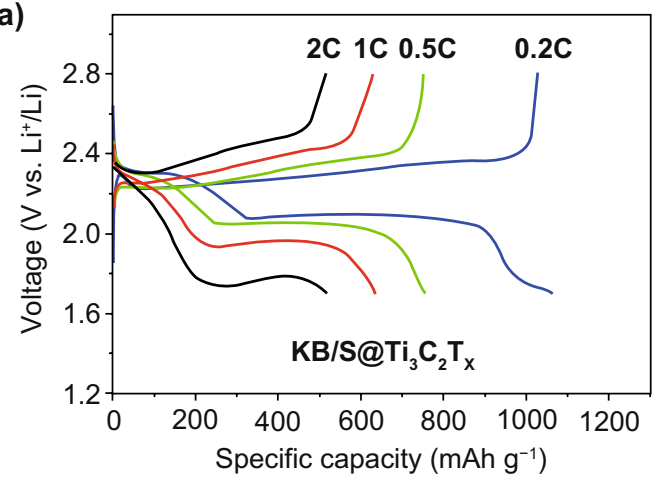

(c)

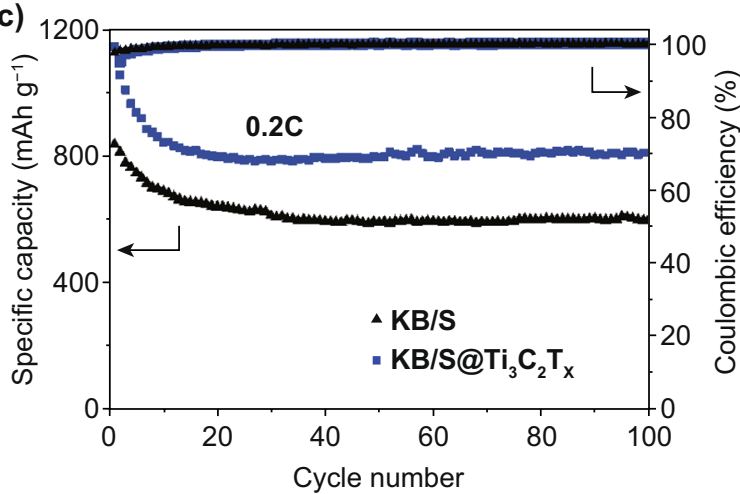

(e)

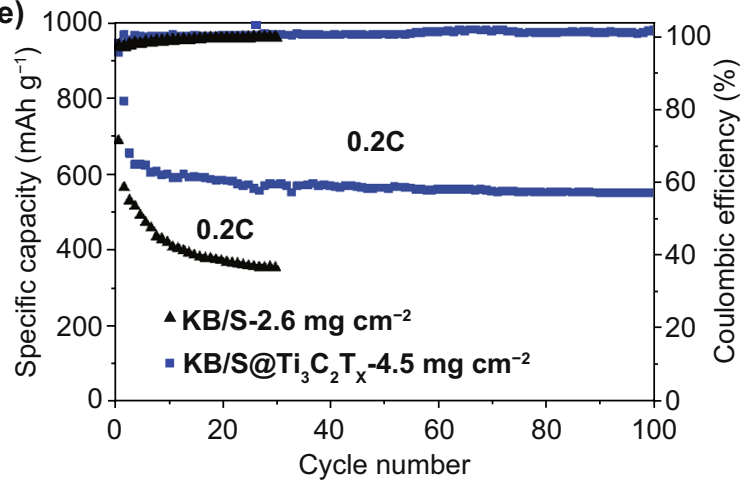

(b)

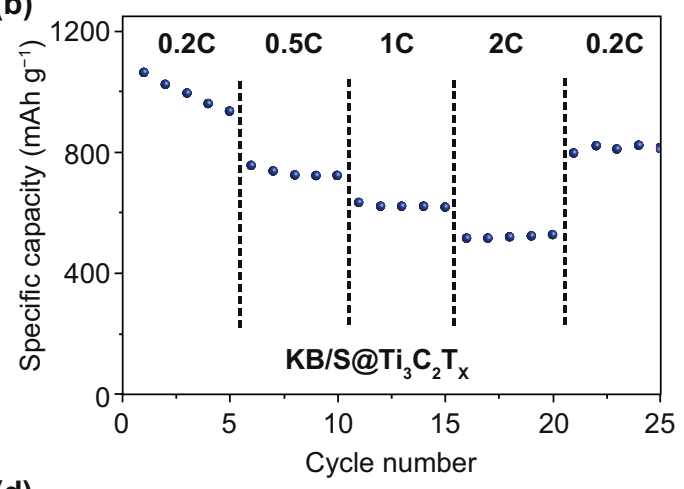

(d)

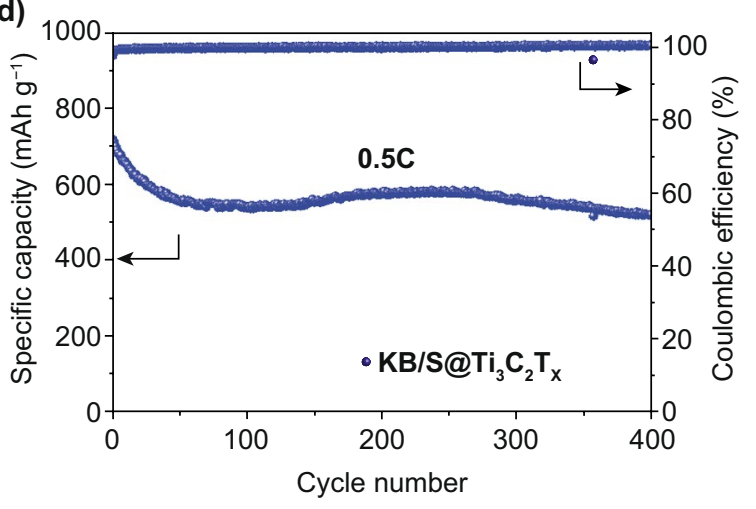

(f)

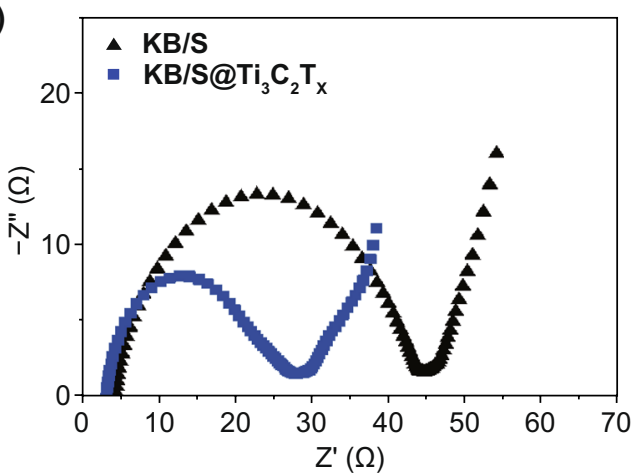

Fig. 3 a Voltage profiles of the $\mathrm{KB} / \mathrm{S} @ \mathrm{Ti}_{3} \mathrm{C}_{2} \mathrm{~T}_{x}$ at various rates ranging from 0.2 to $2 \mathrm{C}$. b Rate performances of $\mathrm{KB} / \mathrm{S} @ \mathrm{Ti}_{3} \mathrm{C}_{2} \mathrm{~T}_{x}$. $\mathbf{c} \mathrm{Cycling}$ performance of $\mathrm{KB} / \mathrm{S}$ and $\mathrm{KB} / \mathrm{S} @ \mathrm{Ti}_{3} \mathrm{C}_{2} \mathrm{~T}_{x}$ at $0.2 \mathrm{C}$. d Long-term cycling of $\mathrm{KB} / \mathrm{S} @ \mathrm{Ti}_{3} \mathrm{C}_{2} \mathrm{~T}_{x}$ at $0.5 \mathrm{C}$. e Cycling performance of KB/S and KB/S@ $\mathrm{Ti}_{3} \mathrm{C}_{2} \mathrm{~T}_{x}$ with high sulfur loading of $2.6 \mathrm{mg} \mathrm{cm}-2$ and $4.5 \mathrm{mg} \mathrm{cm}-2$ at $0.2 \mathrm{C}$, respectively. $\mathbf{f}$ Nyquist plots of the KB/S and $\mathrm{KB} / \mathrm{S} @ \mathrm{Ti}_{3} \mathrm{C}_{2} \mathrm{~T}_{x}$ electrodes

by MXene is evaluated to be higher than most of the sulfur host materials [14], such a low MXene-to-sulfur ratio (3:7 by weight) indicates possible polysulfide escape. Insertion of interlayers between the separator and the cathode has been demonstrated to be a promising approach to further alleviate polysulfide shuttle [44]. MXene nanosheets have been successfully applied as the interlayer to improve the stability of the Li-S battery [45]. In this section, we designed the KB@ $\mathrm{Ti}_{3} \mathrm{C}_{2} \mathrm{~T}_{x}$ coated commercial polypropylene (PP) separators and try to fabricate a lithium sulfur battery with high sulfur areal loading, in the combination of the above-studied $\mathrm{KB} / \mathrm{S} @ \mathrm{Ti}_{3} \mathrm{C}_{2} \mathrm{~T}_{x}$ electrodes.

The merit of the KB carbon in the interlayer is to prevent the restacking of the MXene nanosheets so as to expose most of the active sites on MXene. The composite (KB: $\left.\mathrm{Ti}_{3} \mathrm{C}_{2} \mathrm{~T}_{x}=2: 8, \mathrm{w} / \mathrm{w}\right)$ was prepared by similar selfassembly method discussed above without sulfur in the precursor. The zeta potentials of the composite suggest the 
successful self-assembly between $\mathrm{KB}$ and $\mathrm{Ti}_{3} \mathrm{C}_{2}$ nanosheets (Fig. S7). The SEM image shows the $\mathrm{KB} @ \mathrm{Ti}_{3} \mathrm{C}_{2} \mathrm{~T}_{x}$ composite has an interwoven MXene matrix with homogenously dispersed KB carbon (Fig. 4a). Due to higher $\mathrm{Ti}_{3} \mathrm{C}_{2} \mathrm{~T}_{x}$ ratio, the $\mathrm{KB} @ \mathrm{Ti}_{3} \mathrm{C}_{2} \mathrm{~T}_{x}$ composite is not in spherical morphology as the KB/S@ $\mathrm{Ti}_{3} \mathrm{C}_{2} \mathrm{~T}_{x}$ composite. The specific surface area of the KB@MXene composite is $131 \mathrm{~m}^{2} \mathrm{~g}^{-1}$, as measured by Nitrogen adsorption isotherms (Fig. S8). The increase in surface area of the KB@MXene composite indicates the MXene nanosheets are greatly prevented from re-stacking to promise abundant exposed active sites. Polysulfide adsorption measurements show the strong affinity of $\mathrm{KB} @ \mathrm{Ti}_{3} \mathrm{C}_{2} \mathrm{~T}_{x}$ toward polysulfides, while KB carbon only has minor polysulfide adsorption (Fig. S9). The composite was casted onto separators by doctor blade. SEM image shows the KB @ $\mathrm{Ti}_{3} \mathrm{C}_{2} \mathrm{~T}_{x}$ micron particles are uniformly coated on the surface of separator (Fig. 4b). The mass loading of $\mathrm{KB} @ \mathrm{~T}_{\mathrm{i} 3} \mathrm{C}_{2} \mathrm{~T}_{x}$ is about $0.28 \mathrm{mg} \mathrm{cm}^{-2}$. The thickness is about $3 \mu \mathrm{m}$, accounting for only $3 \%$ of the thickness of the cathode (Fig. 4c). The KB@ $@ \mathrm{Ti}_{3} \mathrm{C}_{2} \mathrm{~T}_{x}$ interlayer, much thinner than most of the reported interlayers $[6,46,47]$, is too thin to significantly affect the volumetric/gravimetric energy density of the Li-S batteries [48]. A comparison with the literatures about the thickness and the areal mass of the interlayer in $\mathrm{Li}-\mathrm{S}$ batteries is summarized in Table $\mathrm{S} 1$. The $\mathrm{KB} @ \mathrm{Ti}_{3} \mathrm{C}_{2} \mathrm{~T}_{x}$ interlayer shows excellent electrochemical performance even at low areal mass and thin thickness. The as-prepared KB@ $\mathrm{Ti}_{3} \mathrm{C}_{2} \mathrm{~T}_{x}$-coated separator maintains the flexibility and excellent mechanical strength, as demonstrated by the foldable shape (Fig. 4d).

In order to verify the $\mathrm{KB} @ \mathrm{Ti}_{3} \mathrm{C}_{2} \mathrm{~T}_{x}$-coated separator has the capacity to restrain the polysulfide shuttle, visualized H-type glass cells with $1 \mathrm{mM} \mathrm{Li}_{2} \mathrm{~S}_{6}$ solution were assembled (Fig. 4e). Polysulfides diffused across the unmodified PP separator quickly, accompanied by color changed of the counter container of the H-cells from colorless to pale yellow within $4 \mathrm{~h}$, indicating uncontrolled polysulfide diffusion. In sharp contrast, the cell with $\mathrm{KB} @ \mathrm{Ti}_{3} \mathrm{C}_{2} \mathrm{~T}_{x}$-coated separator does not have visual difference in $4 \mathrm{~h}$; the solution in the right-side container only started to turn light pale yellow after $8 \mathrm{~h}$. We expect significant improvements to the $\mathrm{Li}-\mathrm{S}$ battery when using this polysulfide diffusion retardant $\mathrm{KB} @ \mathrm{Ti}_{3} \mathrm{C}_{2} \mathrm{~T}_{x}$-coated separator. In addition, we studied the Li metal morphology after cycled in $\mathrm{Li}-\mathrm{S}$ batteries. The SEM image shows a rouge surface of the lithium anode with severe corrosion in the cell with regular separator, whereas the $\mathrm{Li}$ anode $\mathrm{KB} @ \mathrm{Ti}_{3} \mathrm{C}_{2} \mathrm{~T}_{x}$-coated separator is relatively uniform and smooth surface (Fig. S10). The differences could be ascribed to corrosion of the Li metal by polysulfides.

Figure 5 shows the impacts of the $\mathrm{KB} @ \mathrm{Ti}_{3} \mathrm{C}_{2} \mathrm{~T}_{x}$ modified separator to the electrochemical performance of the $\mathrm{Li}-\mathrm{S}$ batteries. Comparisons are made between the cells based on the KB/S@ $\mathrm{Ti}_{3} \mathrm{C}_{2} \mathrm{~T}_{x}$ electrode with and without the modified separators. The cyclic voltammetry (CV) measurements convey that the modified separator promoted the redox kinetics of the sulfur electrode (Fig. 5a). The redox potentials
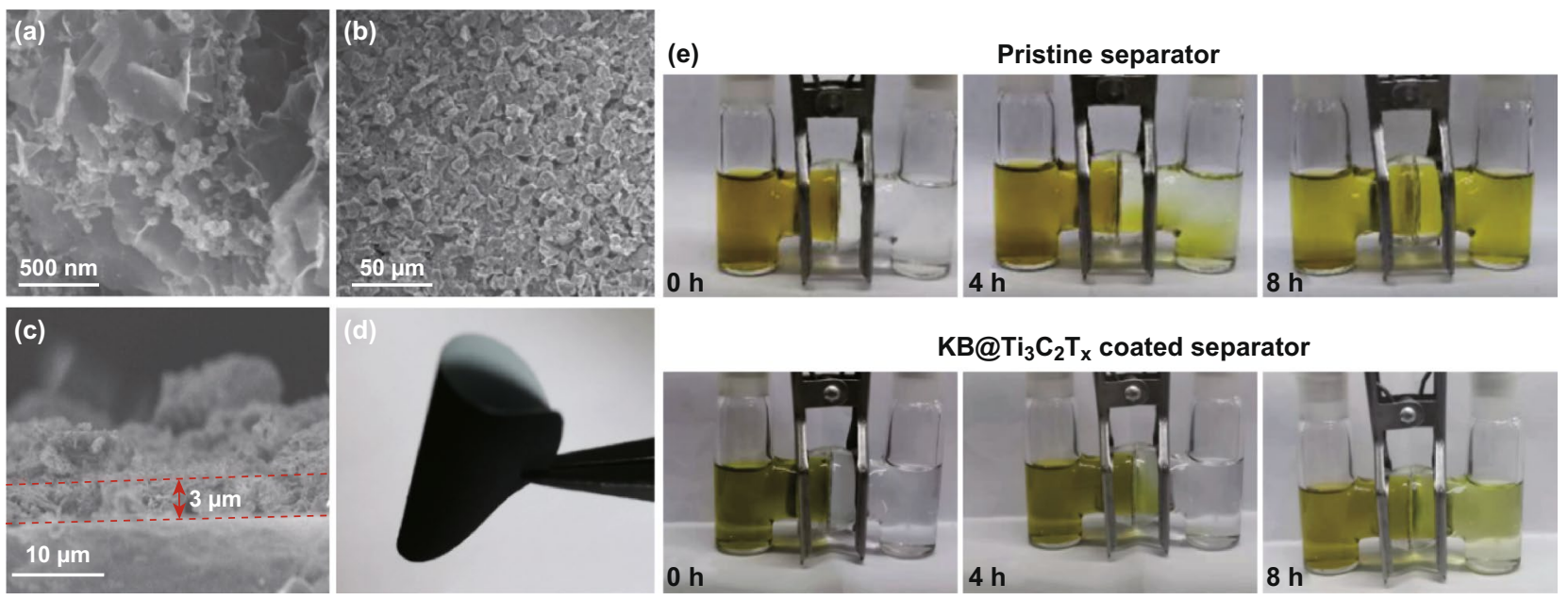

$\mathrm{KB} @ \mathrm{Ti}_{3} \mathrm{C}_{2} \mathrm{~T}_{\mathbf{x}}$ coated separator

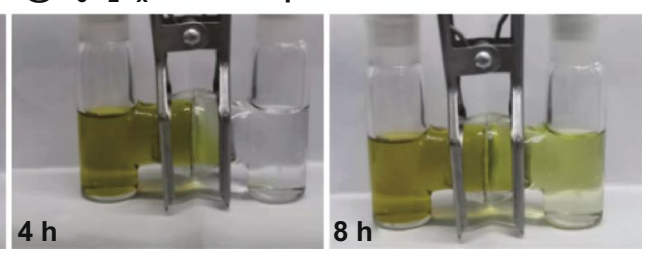

Fig. 4 a SEM image of $\mathrm{KB} @ \mathrm{Ti}_{3} \mathrm{C}_{2} \mathrm{~T}_{x}$. b SEM image of $\mathrm{KB} @ \mathrm{Ti}_{3} \mathrm{C}_{2} \mathrm{~T}_{x}$-coated separator. c Cross-sectional SEM image of KB@ $\mathrm{Ti}_{3} \mathrm{C}_{2} \mathrm{~T}_{x}$-coated separator. d Photograph of the $\mathrm{KB} @ \mathrm{Ti}_{3} \mathrm{C}_{2} \mathrm{~T}_{x}$-coated separator. e Polysulfides permeation measurements with the pristine PP separator and $\mathrm{KB} @$ $\mathrm{Ti}_{3} \mathrm{C}_{2} \mathrm{~T}_{x}$-coated separator 
of the three cells are identical: two cathodic peaks at about 2.3 and $2.0 \mathrm{~V}$ which are corresponding to the formation of the soluble polysulfides $\left(\mathrm{Li}_{2} \mathrm{~S}_{4-8}\right)$ and insoluble polysulfides $\left(\mathrm{Li}_{2} \mathrm{~S}_{2} / \mathrm{Li}_{2} \mathrm{~S}\right)$, respectively. The anodic peak at about $2.5 \mathrm{~V}$ is attributed to the oxidation process of polysulfides to sulfur. It is apparently that the cathodic peak current is increased by the KB@ $\mathrm{Ti}_{3} \mathrm{C}_{2} \mathrm{~T}_{x}$-coated separator. We believe that MXene in the interlayer restrains the escape of polysulfide during the charge/discharge process and offers extra reaction sites for active materials thus additional electron flow is gained. The modified separator also decreases the resistance of the cell as shown by the Nyquist plots (Fig. S11). The quasisemicircle at the high-frequency region is attributed to the charge transfer impedance $\left(R_{c t}\right)$ [49]. This indicates that the $\mathrm{KB} @ \mathrm{Ti}_{3} \mathrm{C}_{2} \mathrm{~T}_{x}$ interlayer can remarkably activate the electrochemical reaction and promote the charge transfer property. The EIS of different Li-S cells are measured after cycling, as shown in Fig. S12. We further fitted the curves to compare the change of $R_{s e i}$ and $R_{c t}$ during cycling by using the equivalent circuit shown in Fig. S12 d, e. The fitted values are listed in Table S2. Apparently, the $R_{c t}$ of the KB/S@ $\mathrm{Ti}_{3} \mathrm{C}_{2} \mathrm{~T}_{x}$ electrode and KB/S@ $\mathrm{Ti}_{3} \mathrm{C}_{2} \mathrm{~T}_{x}$ electrode with $\mathrm{KB} @ \mathrm{Ti}_{3} \mathrm{C}_{2} \mathrm{~T}_{x}$ interlayer are smaller than the $\mathrm{KB} / \mathrm{S}$ electrode, which is owing to the high conductivity of MXene. The $R_{s e i}$ and $R_{c t}$ of KB/S electrode during cycling, indicative of serious polysulfide dissolution which forms passivation layer on the electrode surface. However, $R_{\text {sei }}$ of the $\mathrm{KB} / \mathrm{S} @ \mathrm{Ti}_{3} \mathrm{C}_{2} \mathrm{~T}_{x}$ electrode or the KB/S@ $\mathrm{Ti}_{3} \mathrm{C}_{2} \mathrm{~T}_{x}$ electrode with $\mathrm{KB} @ \mathrm{Ti}_{3} \mathrm{C}_{2} \mathrm{~T}_{x}$ interlayer is decreasing during cycling, suggesting the escape of polysulfide is impeded by the secondary particle structure and the interlayer.

A straight conclusion could be made that the KB@ $\mathrm{Ti}_{3} \mathrm{C}_{2} \mathrm{~T}_{x}$ modified separator improves the specific capacity of the battery, i.e., 1281 versus $1062 \mathrm{mAh} \mathrm{g}^{-1}$ with the pristine separator at $0.2 \mathrm{C}$. (Figs. 3a, 5b). This is consistent with the CV curves in Fig. 5a, in which the modified separator activates the dissolved polysulfide in the electrolyte; thus, a higher specific capacity was delivered. The cells with the $\mathrm{KB} @ \mathrm{Ti}_{3} \mathrm{C}_{2} \mathrm{~T}_{x}$ modified separator also demonstrate better rate performance, as shown in Fig. 5c. Remarkably, it delivers $1014 \mathrm{mAh} \mathrm{g}^{-1}$ after 80 cycles when the current density is adjusted back to $0.2 \mathrm{C}$. The cells with the $\mathrm{KB} @ \mathrm{Ti}_{3} \mathrm{C}_{2} \mathrm{~T}_{x}$ modified separator also have better cycling performance at 1 $\mathrm{C}$, as shown in Fig. 5d. The cell displays an initial discharge capacity of $880 \mathrm{mAh} \mathrm{g}^{-1}$, and still retains a considerable capacity of $629 \mathrm{mAh} \mathrm{g}^{-1}$ after 400 cycles, corresponding to a decay of $0.071 \%$ per cycle. In order to illustrate the role of $\mathrm{KB} @ \mathrm{Ti}_{3} \mathrm{C}_{2} \mathrm{~T}_{X}$ interlayer, we paired the $\mathrm{KB} / \mathrm{S}$ electrode with the KB@ $\mathrm{Ti}_{3} \mathrm{C}_{2} \mathrm{~T}_{X}$ interlayer, as shown in Fig. S13. The cell displays an initial discharge capacity of $754 \mathrm{mAh} \mathrm{g}^{-1}$ at $1 \mathrm{C}$, and still retains a considerable capacity of $514 \mathrm{mAh}$ $\mathrm{g}^{-1}$ after 400 cycles. The improvement by using the KB@ $\mathrm{Ti}_{3} \mathrm{C}_{2} \mathrm{~T}_{X}$ interlayer compared to the cell with regular separators (Fig. 3c), further indicating that $\mathrm{KB} @ \mathrm{Ti}_{3} \mathrm{C}_{2} \mathrm{~T}_{X}$ interlayer could hinder the polysulfide shuttle and improves sulfur utilization. We compared the performance with other publications with low sulfur loading in Table S3, because most of the available publications are reported with sulfur loading $<2 \mathrm{mg} \mathrm{cm}^{-2}$. It shows that the comprehensive engineering of the MXene nanosheets afford to a high capacity and high capacity retention for long-term cycling.

Benefiting from the promising microstructural KB/S@ $\mathrm{Ti}_{3} \mathrm{C}_{2} \mathrm{~T}_{x}$ electrode and the effective interlayer, electrodes with higher sulfur loading were also tested (Fig. 5e). The sulfur areal loading is increased to $5.6 \mathrm{mg} \mathrm{cm}^{-2}$. Because of the minimal thickness of the interlayer, it does not absorb much electrolyte as other reported interlayer did. Thus it is possible to cycle the cell with relatively lean electrolyte of E/S ratio of $7 \mu \mathrm{L} / \mathrm{mg}$. The batteries were activated by cycling at $0.05 \mathrm{C}$ for the first two cycles, followed by $0.2 \mathrm{C}$ in the subsequent cycles. The areal capacity is a critical parameter but always being neglected among the Li-S community [50]. Correspondingly, we have plotted area capacity and specific capacity in Fig. 5e. The discharge capacities of cell were $1137 \mathrm{~mA} \mathrm{~h} \mathrm{~g}^{-1}$ at $0.05 \mathrm{C}$ and $810 \mathrm{mAh} \mathrm{g}^{-1}$ at $0.2 \mathrm{C}$, and the corresponding areal capacities were $6.4 \mathrm{mAh} \mathrm{cm}^{-2}$ and $4.5 \mathrm{mAh} \mathrm{cm}^{-2}$, respectively. The cell delivers about $600 \mathrm{mAh} \mathrm{g}^{-1}$ capacity after 100 cycles. We compared our work with other recent publications with high sulphur loading that involve MXenes in the electrodes or in the separators, as shown in Table S4. It shows that our work is superior or at least comparable to these references. This is owing to the interwoven KB@ $\mathrm{Ti}_{3} \mathrm{C}_{2} \mathrm{~T}_{X}$ composite as well as the modified separator, which not only provides superior polysulfide interaction and maintains the electrode integrality bearing the volume expansion/shrinkage, but also further retards the polysulfide cross-diffusion that possibly escaped from the cathode. We also believe this performance is competitive to the recently reported interlayer works with high sulfur areal loading. Moreover, our results are obtained at a more lean electrolyte condition [51]. 

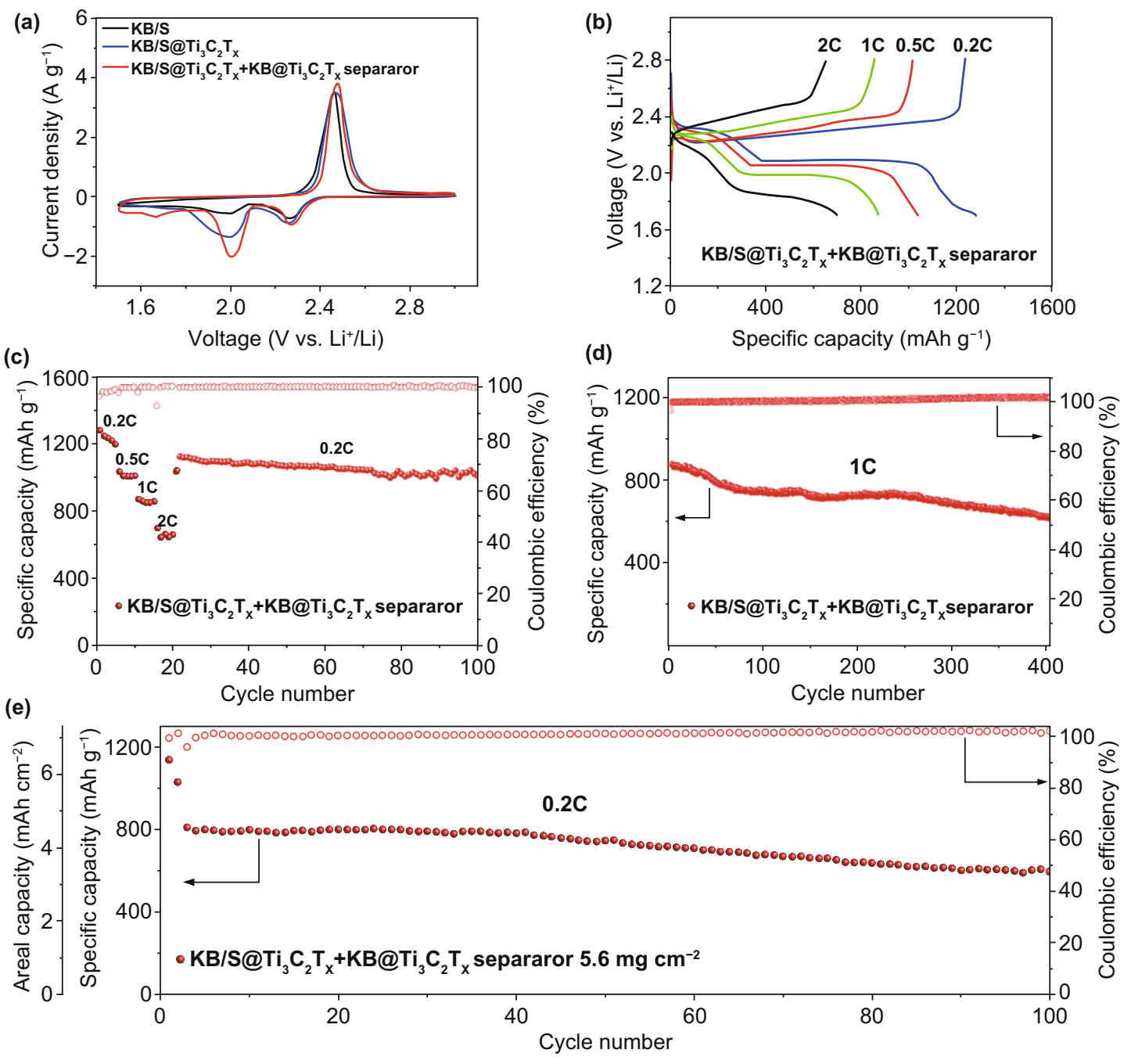

Fig. 5 a CV profiles of KB/S and KB/S@ $\mathrm{Ti}_{3} \mathrm{C}_{2} \mathrm{~T}_{x}$, with the pristine separators, and the $\mathrm{KB} / \mathrm{S} @ \mathrm{Ti}_{3} \mathrm{C}_{2} \mathrm{~T}_{x}$ electrode with the KB@Ti ${ }_{3} \mathrm{C}_{2} \mathrm{~T}_{x}$ modified separator. $\mathbf{b}$ Voltage profiles of the KB/S@ $\mathrm{Ti}_{3} \mathrm{C}_{2} \mathrm{~T}_{x}$ cell with the $\mathrm{KB} @ \mathrm{Ti}_{3} \mathrm{C}_{2} \mathrm{~T}_{x}$ modified separator at various rates ranging from 0.2 to $2 \mathrm{C}$. $\mathbf{c}$ Rate performances, $\mathbf{d}$ long-term cycling performance at $1 \mathrm{C}$ of the $\mathrm{KB} / \mathrm{S} @ \mathrm{Ti}_{3} \mathrm{C}_{2} \mathrm{~T}_{x}$ electrode with the $\mathrm{KB} @ \mathrm{Ti}_{3} \mathrm{C}_{2} \mathrm{~T}_{x}$ separator. e Cycling performance with high sulfur loading of $5.6 \mathrm{mg} \mathrm{cm}^{-2}$ at $0.2 \mathrm{C}$

\section{Conclusions}

We have demonstrated a comprehensive design of material and cell construction aimed at achieving improved $\mathrm{Li}-\mathrm{S}$ battery with high sulfur areal loading. The key materials are based on the fascinating MXene phase with known affinity to the polysulfide species. Material engineering for the sulfur host and the interlayer coated on separator were conducted through electrostatic self-assembly approach. The prepared KB/S@ $\mathrm{Ti}_{3} \mathrm{C}_{2} \mathrm{~T}_{x}$ has an interwoven structure in which the $\mathrm{KB}$ carbon core improves the electric conductivity, while the MXene nanosheets guarantees physi-/chemisorption of the soluble polysulfide species. More importantly, the interwoven structure benefits the structure integrality for the volume expansion/shrinkage of the sulfur electrode. To further retard the polysulfide that possibly escaped from the cathode, the KB@ $\mathrm{Ti}_{3} \mathrm{C}_{2} \mathrm{~T}_{x}$ was coated on the separator to function as an interlayer (about $3 \mu \mathrm{m}$ ). This interlayer does not sacrifice the volumetric/gravimetric energy density because of the minimal thickness and weight ratio; however, it retards and activates the dissolved polysulfide, improving the overall sulfur utilization. By coupling the robust KB/S@ $\mathrm{Ti}_{3} \mathrm{C}_{2} \mathrm{~T}_{x}$ cathode and the effective $\mathrm{KB} @ \mathrm{Ti}_{3} \mathrm{C}_{2} \mathrm{~T}_{x}$ modified separator, we achieved a stable Li-S battery with high sulfur areal 
loading at relatively lean electrolyte. Further development of the high energy density Li-S batteries that cycled at $E / S<5 \mu \mathrm{L} \mathrm{mg}^{-1}$ via electrolyte formula and electrode architecture optimization is under investigation in our laboratory.

Acknowledgements This work was financially supported by National Key Research and Development Program (No. 2019YFA0210600), the Major Technological Innovation Project of Hubei Science and Technology Department (No. 2019AAA164), the National Natural Science Foundation of China (No. 51972107), and the Innovative Research Groups of Hunan Province (No. 2019JJ10001).

Open Access This article is licensed under a Creative Commons Attribution 4.0 International License, which permits use, sharing, adaptation, distribution and reproduction in any medium or format, as long as you give appropriate credit to the original author(s) and the source, provide a link to the Creative Commons licence, and indicate if changes were made. The images or other third party material in this article are included in the article's Creative Commons licence, unless indicated otherwise in a credit line to the material. If material is not included in the article's Creative Commons licence and your intended use is not permitted by statutory regulation or exceeds the permitted use, you will need to obtain permission directly from the copyright holder. To view a copy of this licence, visit http://creativecommons.org/licenses/by/4.0/.

Electronic supplementary material The online version of this article (https://doi.org/10.1007/s40820-020-00449-7) contains supplementary material, which is available to authorized users.

\section{References}

1. P.G. Bruce, S.A. Freunberger, L.J. Hardwick, J.M. Tarascon, $\mathrm{Li}-\mathrm{O}_{2}$ and $\mathrm{Li}-\mathrm{S}$ batteries with high energy storage. Nat. Mater. 11, 19-29 (2012). https://doi.org/10.1038/nmat3191

2. Z.W. Seh, Y.M. Sun, Q. Zhang, Y. Cui, Designing high-energy lithium-sulfur batteries. Chem. Soc. Rev. 45(20), 5605-5634 (2016). https://doi.org/10.1039/c5cs00410a

3. M. Zhao, B.Q. Li, H.J. Peng, H. Yuan, J.Y. Wei, J.Q. Huang, Challenges and opportunities towards practical lithium-sulfur batteries under lean electrolyte conditions. Angew. Chem. Int. Ed. 132, 2-20 (2020). https://doi.org/10.1002/ange.201909339

4. X. Liang, A. Garsuch, L.F. Nazar, Sulfur cathodes based on conductive mxene nanosheets for high-performance lithiumsulfur batteries. Angew. Chem. Int. Ed. 54(13), 3907-3911 (2015). https://doi.org/10.1002/anie.201410174

5. X. Wu, N. Liu, M. Wang, Y. Qiu, B. Guan, D. Tian, N. Zhang, A class of catalysts of $\mathrm{BiOX}(\mathrm{X}=\mathrm{Cl}, \mathrm{Br}, \mathrm{I})$ for anchoring polysulfides and accelerating redox reaction in lithium sulfur batteries. ACS Nano 13(11), 13109-13115 (2019). https://doi. org/10.1021/acsnano.9b05908
6. S. Xin, L. Gu, N.H. Zhao, Y.X. Yin, L.J. Zhou, Y.G. Guo, L.J. Wan, Smaller sulfur molecules promise better lithium-sulfur batteries. J. Am. Chem. Soc. 134(45), 18510-18513 (2012). https://doi.org/10.1021/ja308170k

7. L. Wang, J. Liu, S. Yuan, Y. Wang, Y. Xia, To mitigate selfdischarge of lithium-sulfur batteries by optimizing ionic liquid electrolytes. Energy Environ. Sci. 9(1), 224-231 (2016). https ://doi.org/10.1039/C5EE02837J

8. Z. Xu, J. Wang, J. Yang, X. Miao, R. Chen, J. Qian, R. Miao, Enhanced performance of a lithium-sulfur battery using a carbonate-based electrolyte. Angew. Chem. Int. Ed. 55(35), 10372-10375 (2016). https://doi.org/10.1002/anie.201605931

9. H. Tang, W. Li, L. Pan, K. Tu, F. Du, T. Qiu, C. Zhang, A robust, freestanding mxene-sulfur conductive paper for longlifetime Li-S batteries. Adv. Funct. Mater. (2019). https://doi. org/10.1002/adfm.201901907

10. L. Qie, A. Manthiram, A facile layer-by-layer approach for high-areal-capacity sulfur cathodes. Adv. Mater. 27(10), 1694-1700 (2015). https://doi.org/10.1002/adma.201405689

11. Y.L. Ding, P. Kopold, K. Hahn, P.A. van Aken, J. Maier, Y. $\mathrm{Yu}$, Facile solid-state growth of 3D well-interconnected nitrogen-rich carbon nanotube-graphene hybrid architectures for lithium-sulfur batteries. Adv. Funct. Mater. 26(7), 1112-1119 (2016). https://doi.org/10.1002/adfm.201504294

12. H.J. Peng, J.Q. Huang, X.B. Cheng, Q. Zhang, Review on high-loading and high-energy lithium-sulfur batteries. Adv. Energy Mater. 7(24), 1700260 (2017). https://doi.org/10.1002/ aenm.201700260

13. Q. Pang, X. Liang, C.Y. Kwok, L.F. Nazar, Advances in lithium-sulfur batteries based on multifunctional cathodes and electrolytes. Nat. Energy 1(9), 16132 (2016). https://doi. org/10.1038/nenergy.2016.132

14. W. Sun, C. Liu, Y. Li, S. Luo, S. Liu, X. Hong, C. Zheng, Rational construction of $\mathrm{Fe}_{2} \mathrm{~N} @ \mathrm{C}$ yolk-shell nanoboxes as multifunctional hosts for ultralong lithium-sulfur batteries. ACS Nano 13(10), 12137-12147 (2019). https://doi. org/10.1021/acsnano.9b06629

15. M. Yu, S. Zhou, Z. Wang, W. Pei, X. Liu, C. Liu, J. Qiu, A molecular-cage strategy enabling efficient chemisorptionelectrocatalytic interface in nanostructured Li2S cathode for Li metal-free rechargeable cells with high energy. Adv. Funct. Mater. 29, 1905986 (2019). https://doi.org/10.1002/ adfm.201905986

16. X. Chen, S. Zeng, H. Muheiyati, Y. Zhai, C. Li, X. Ding, Y. Qian, Double-shelled Ni-Fe-P/N-doped carbon nanobox derived from Prussian blue analogue as electrode material for K-ion batteries and Li-S batteries. ACS Energy Lett. 4, 14961504 (2019). https://doi.org/10.1021/acsenergylett.9b00573

17. X. Liang, Y. Rangom, C.Y. Kwok, Q. Pang, L.F. Nazar, Interwoven MXene nanosheet/carbon-nanotube composites as Li-S cathode hosts. Adv. Mater. 29(3), 1603040 (2017). https://doi. org/10.1002/adma.201603040

18. X. Liang, C. Hart, Q. Pang, A. Garsuch, T. Weiss, L.F. Nazar, A highly efficient polysulfide mediator for lithium-sulfur batteries. Nat. Commun. 6, 5682 (2015). https://doi.org/10.1038/ ncomms6682 
19. B. Anasori, M.R. Lukatskaya, Y. Gogotsi, 2D metal carbides and nitrides (MXenes) for energy storage. Nat. Rev. Mater. 2(2), 16098 (2017). https://doi.org/10.1038/natrevmats .2016 .98

20. X. Tang, D. Zhou, P. Li, X. Guo, B. Sun et al., MXene-based dendrite-free potassium metal batteries. Adv. Mater. (2019). https://doi.org/10.1002/adma.201906739

21. X. Tang, D. Zhou, P. Li, X. Guo, C.Y. Wang, F.Y. Kang, B.H. Li, G.X. Wang, High-performance quasi-solid-state MXenebased Li-I batteries. ACS Cent. Sci. 5(2), 365-373 (2019). https://doi.org/10.1021/acscentsci.8b00921

22. X.J. Hong, C.L. Song, Y. Yang, H.C. Tan, G.H. Li, Y.P. Cai, H. Wang, Cerium based Metal-Organic frameworks as an efficient separator coating catalyzing the conversion of polysulfides for high performance lithium-sulfur batteries. ACS Nano 13(2), 1923-1931 (2019). https://doi.org/10.1021/acsnano.8b08155

23. D. Tian, X. Song, M. Wang, X. Wu, Y. Qiu, B. Guan, K. Sun, MoN supported on graphene as a bifunctional interlayer for advanced Li-S batteries. Adv. Energy Mater. 6, 1901940 (2019). https://doi.org/10.1002/aenm.201901940

24. M. Zhao, H.J. Peng, Z.W. Zhang, B.Q. Li, X. Chen et al., Activating inert metallic compounds for high-rate lithiumsulfur batteries through in situ etching of extrinsic metal. Angew. Chem. Int. Ed. 58(12), 3779-3783 (2019). https:// doi.org/10.1002/anie.201812062

25. D. Guo, F. Ming, H. Su, Y. Wu, W. Wahyudi, M. Li, Y. Li, Z.P. Lai, MXene based self-assembled cathode and antifouling separator for high-rate and dendrite-inhibited Li-S battery. Nano Energy 61, 478-485 (2019). https://doi.org/10.1016/j. nanoen.2019.05.011

26. C. Lin, W. Zhang, L. Wang, Z. Wang, W. Zhao, W. Duan, J. Jin, A few-layered $\mathrm{Ti}_{3} \mathrm{C}_{2}$ nanosheet/glass fiber composite separator as a lithium polysulphide reservoir for high-performance lithium-sulfur batteries. J. Mater. Chem. A 4(16), 5993-5998 (2016). https://doi.org/10.1039/C5TA10307J

27. S.H. Chung, A. Manthiram, Rational design of statically and dynamically stable lithium-sulfur batteries with high sulfur loading and low electrolyte/sulfur ratio. Adv. Mater. 30(6), 1705951 (2018). https://doi.org/10.1002/adma.201705951

28. J. Ma, Z. Fang, Y. Yan, Z. Yang, L. Gu, Y.S. Hu, X. Huang, Novel large-scale synthesis of a C/S nanocomposite with mixed conducting networks through a spray drying approach for Li-S batteries. Adv. Energy Mater. 5(16), 1500046 (2015). https://doi.org/10.1002/aenm.201500046

29. G. Ai, Y. Dai, W. Mao, H. Zhao, Y. Fu, X. Song, G. Liu, Biomimetic ant-nest electrode structures for high sulfur ratio lithium-sulfur batteries. Nano Lett. 16(9), 5365-5372 (2016). https://doi.org/10.1021/acs.nanolett.6b01434

30. H.J. Peng, W.T. Xu, L. Zhu, D.W. Wang, J.Q. Huang, X.B. Cheng, Q. Zhang, 3D carbonaceous current collectors: the origin of enhanced cycling stability for high-sulfur-loading lithium-sulfur batteries. Adv. Funct. Mater. 26(35), 6351-6358 (2016). https://doi.org/10.1002/adfm.201602071

31. G. Hu, C. Xu, Z. Sun, S. Wang, H.M. Cheng, F. Li, W. Ren, 3D graphene-foam-reduced-graphene-oxide hybrid nested hierarchical networks for high-performance $\mathrm{Li}-\mathrm{S}$ batteries. Adv. Mater. 28(8), 1603-1609 (2016). https://doi.org/10.1002/ adma.201504765

32. Q. Pang, X. Liang, C.Y. Kwok, J. Kulisch, L.F. Nazar, A comprehensive approach toward stable lithium-sulfur batteries with high volumetric energy density. Adv. Energy Mater. 7(6), 1601630 (2017). https://doi.org/10.1002/aenm.201601630

33. L. Wang, Z. Dong, D. Wang, F. Zhang, J. Jin, Covalent bond glued sulfur nanosheet-based cathode integration for longcycle-life Li-S batteries. Nano Lett. 13(12), 6244-6250 (2013). https://doi.org/10.1021/n1403715h

34. M. Ghidiu, Lukatskaya, M.-Q. Zhao, Y. Gogotsi, M.W. Barsoum, Conductive two-dimensional titanium carbide 'clay' with high volumetric capacitance. Nature 516, 78-81 (2014). https://doi.org/10.1038/nature13970

35. L. Zhong, K. Yang, R. Guan, L. Wang, S. Wang, D. Han, Y. Meng, Toward theoretically cycling-stable lithium-sulfur battery using a foldable and compositionally heterogeneous cathode. ACS Appl. Mater. Interfaces 9(50), 43640-43647 (2017). https://doi.org/10.1021/acsami.7b13247

36. M. Alhabeb, K. Maleski, B. Anasori, P. Lelyukh, L. Clark, S. Sin, Y. Gogotsi, Guidelines for synthesis and processing of two-dimensional titanium carbide $\left(\mathrm{Ti}_{3} \mathrm{C}_{2} \mathrm{~T}_{\mathrm{x}} \mathrm{MXene}\right)$. Chem. Mater. 29(18), 7633-7644 (2017). https://doi.org/10.1021/acs. chemmater.7b02847

37. X. Xie, M.Q. Zhao, B. Anasori, K. Maleski, C.E. Ren, J. Li, Y. Gogotsi, Porous heterostructured mxene/carbon nanotube composite paper with high volumetric capacity for sodiumbased energy storage devices. Nano Energy 26, 513-523 (2016). https://doi.org/10.1016/j.nanoen.2016.06.005

38. D. Yu, L. Dai, Self-assembled graphene/carbon nanotube hybrid films for supercapacitors. J. Phys. Chem. Lett. 1(2), 467-470 (2009). https://doi.org/10.1021/jz9003137

39. J.M. Zheng, D.P. Lva, M. Gu, C.M. Wang, J.G. Zhang, J. Liu, J. Xiao, How to obtain reproducible results for lithium sulfur batteries? J. Electrochem. Soc. 160(11), A2288-A2292 (2013). https://doi.org/10.1149/2.106311jes

40. W.Z. Bao, D.W. Su, W.X. Zhang, X. Guo, G.X. Wang, 3D metal carbide@mesoporous carbon hybrid architecture as a new polysulfide reservoir for lithium-sulfur batteries. Adv. Funct. Mater. 26, 8746-8756 (2016). https://doi.org/10.1002/ adfm.201603704

41. A. Fu, C.Z. Wang, F. Pei, J.Q. Cui, X. Fang, N.F. Zheng, Recent advances in hollow porous carbon materials for lithium-sulfur batteries. Small 1804786 (2019). https://doi. org/10.1002/smll.201804786

42. Y.K. Son, J.S. Lee, Y. Son, J.H. Jang, J. Cho, Recent advances in lithium sulfide cathode materials and their use in lithium sulfur batteries. Adv. Energy Mater. 5(16), 1500110 (2015). https://doi.org/10.1002/aenm.201500110

43. J. Zhang, J.Y. Li, W.P. Wang, X.H. Zhang, X.H. Tan, W.G. Chu, Y.G. Guo, Microemulsion assisted assembly of 3D porous S/Graphene@g- $\mathrm{C}_{3} \mathrm{~N}_{4}$ hybrid sponge as free-standing cathodes for high energy density Li-S batteries. Adv. Energy 
Mater. 8, 1702839 (2018). https://doi.org/10.1002/aenm.20170 2839

44. H.J. Peng, D.W. Wang, J.Q. Huang, X.B. Cheng, Z. Yuan, F. Wei, Q. Zhang, Janus separator of polypropylene-supported cellular graphene framework for sulfur cathodes with high utilization in lithium-sulfur batteries. Adv. Sci. 3, 1500268 (2016). https://doi.org/10.1002/advs.201500268

45. J. Song, D. Su, X. Xie, X. Guo, W. Bao, G. Shao, G. Wang, Immobilizing polysulfides with mxene-functionalized separators for stable lithium-sulfur batteries. ACS Appl. Mater. Interfaces 8(43), 29427-29433 (2016). https://doi. org/10.1021/acsami.6b09027

46. H.Q. Wang, W.C. Zhang, H.K. Liu, Z.P. Guo, A strategy for configuration of an integrated flexible sulfur cathode for highperformance lithium-sulfur batteries. Angew. Chem. Int. Ed. 55(12), 3992-3996 (2016). https://doi.org/10.1002/anie.20151 1673

47. J.X. Song, T. Xu, M.L. Gordin, P.Y. Zhu, D.P. Lv et al., Nitrogen-doped mesoporous carbon promoted chemical adsorption of sulfur and fabrication of high-areal-capacity sulfur cathode with exceptional cycling stability for lithium-sulfur batteries.
Adv. Funct. Mater. 24(9), 1243-1250 (2014). https://doi. org/10.1002/adfm.201302631

48. H.B. Yao, K. Yan, W.Y. Li, G.Y. Zheng, D.S. Kong et al., Improved lithium-sulfur batteries with a conductive coating on the separator to prevent the accumulation of inactive s-related species at the cathode-separator interface. Energy Environ. Sci. 7(10), 3381-3390 (2014). https://doi. org/10.1039/C4EE01377H

49. J. Balach, T. Jaumann, M. Klose, S. Oswald, J. Eckert, L. Giebeler, Functional mesoporous carbon-coated separator for long-life, high-energy lithium-sulfur batteries. Adv. Funct. Mater. 25(33), 5285-5291 (2015). https://doi.org/10.1002/ adfm.201502251

50. A. Bhargav, J. He, A. Gupta, A. Manthiram, Lithium-sulfur batteries: attaining the critical metrics. Joule 4(2), 285-291 (2020). https://doi.org/10.1016/j.joule.2020.01.001

51. L. Jiao, C. Zhang, C. Geng, S. Wu, H. Li, W. Lv, W. Ling, Capture and catalytic conversion of polysulfides by in situ built $\mathrm{TiO}_{2}$-mxene heterostructures for lithium-sulfur batteries. Adv. Energy Mater. 9(19), 1900219 (2019). https://doi. org/10.1002/aenm.201900219 